\title{
EVENTOS DE PRECIPITAÇÕES EXTREMAS NA AMAZÔNIA OCIDENTAL: RONDÔNIA - BRASIL
}

\author{
SOUZA, Vinicius Alexandre Sikora de - vass1000@hotmail.com \\ Mestrando em Engenharia Civil (COPPE/UFRJ) \\ NUNES, Marcos Leandro Alves - marcosbatarelli@hotmail.com \\ Mestre em Engenharia Civil (COPPE/UFRJ) \\ FRANCENER, Sandra Ferronatto - sandraffrancener@hotmail.com \\ Engenheira Ambiental (UNIR) \\ ROSA, Ana Lúcia Denardin da - eng.analucia@yahoo.com.br \\ Professora do Departamento de Engenharia Ambiental (UNIR).
}

\begin{abstract}
RESUMO: Este estudo objetivou analisar a ocorrência de eventos pluviométricos extremos a partir dos dados de precipitação das estações pluviométricas instaladas no estado de Rondônia. Utilizou-se 41 estações pluviométricas com séries históricas acima de 10 anos. Posteriormente tais dados foram analisados pela distribuição de Gumbel, sendo os mesmos relacionados, por meio da desagregação de chuva diária, para períodos de retorno compreendendo 2 a 100 anos e durações pluviométricas de 5 minutos a 24 horas. As séries históricas utilizadas revelaram que a média das chuvas máximas de "um dia", no estado de Rondônia encontrou-se variando de aproximadamente 71,341 a $173,542 \mathrm{~mm} /$ dia, além disso, observou-se que possíveis atuações de fenômenos climáticos como o El Niño e La Niña na região analisada pode ter gerado, respectivamente, as reduções e aumentos na ocorrência de eventos pluviométricos extremos.
\end{abstract}

Palavras-chave: Chuvas intensas; Curva IDF; Impactos socioambientais; Hidroestatística.

EXTREME PRECIPITATION EVENTS IN WESTERN OF AMAZONIA: RONDÔNIA - BRAZIL

ABSTRACT: This study aimed to estimate the Intensity - Duration - Frequency (IDF) function extreme rainfall to State of Rondônia. We used 41 rainfall stations with historical series over 10 years. These data were analyzed by the Gumbel distribution, and they are related through the disaggregation of daily rainfall for return periods comprising 2 to 100 years and rainfall durations from 5 minutes to 24 hours. The time series used showed that rainfall maximum average of "one day", in the Rondônia state it was found ranging from about 71,341 to $173,542 \mathrm{~mm} /$ day, and also it were noticed that possible performances of climatic phenomena like El Niño and La Niña in the analyzed region can be what generates the reductions and increases in the occurrence of extreme rainfall events respectively.

Keywords: Heavy rainfalls, IDF Curve, Social and environmental impacts; Hydro statistics.

\section{INTRODUÇÃO}

O Brasil apresentou após a década de 60 um crescimento significativo da população urbana, principalmente, nas regiões Centro-Oeste e Norte do país (SANTOS, 2008). A ocorrência deste fenômeno, no entanto, não veio atrelada a um planejamento urbano que garantisse uma infraestrutura adequada nas cidades (FERREIRA, 2000). 
Os efeitos desse processo ocorrido de forma desorganizada se propagam por todo o aparelhamento urbano relativo aos recursos hídricos. Principalmente ao que concerne ao planejamento e construção de obras hidráulicas e hidrológicas, para minimizar os impactos socioambientais como as enchentes, pelo planejamento da drenagem urbana (OLIVEIRA et al., 2011; TUCCI, 2007).

O conhecimento de eventos hidrológicos extremos é um requisito em projetos de drenagem, impermeabilização e outras obras de engenharia, seja em áreas urbanas ou rurais, isso porque, permite que o projetista considere os riscos existentes com a execução da obra e associe à melhor alternativa, do ponto de vista econômico, sem desconsiderar as questões técnicas de desempenho e segurança.

A precipitação pluviométrica, dentre os elementos hidrológicos, é o que mais interfere na vida humana, uma vez que, se configura como a principal entrada de água no sistema hidrológico, tornando outras variantes como a vazão e a infiltração, intimamente ligadas a sua ocorrência. Em virtude de sua larga influência sob áreas povoadas, positivas ou não, a chuva pode ser considera a principal forma de suprimento hídrico para as atividades humanas e econômicas (ALMEIDA et al., 2011).

Dessa forma, torna-se de grande importância o conhecimento e a previsão das características das precipitações pluviométricas, destacando a elucidação de sua intensidade máxima, duração desse fenômeno e o período que tal evento possa voltar a ocorrer.

No Brasil, os volumes precipitados são essencialmente quantificados pelas estações pluviométricas em registros denominados de chuvas diárias e, constituem as informações mais acessíveis, não somente pelo tamanho das séries, mas também pela densidade das redes (HERNANDEZ, 2008).

Em virtude desta problemática, o método de desagregação da chuva de 24 horas, da Companhia de Tecnologia de Saneamento Ambiental do Estado de São Paulo - CETESB (1979 apud TUCCI, 2009) apresenta-se como uma solução, pois o mesmo gera séries sintéticas com duração em intervalos menores, por meio de coeficientes que transformam chuva de $24 \mathrm{~h}$ em outras de menor duração.

Ressalta-se que o território nacional carece do desenvolvimento e análise de trabalhos que investiguem esse fenômeno, como o estado de Rondônia, localizado na Amazônia Ocidental. Embora exista uma rede de registro de dados pluviométrico no estado, a disponibilização de informações de chuvas intensas ainda é insipiente. Os trabalhos realizados pelo SIPAM não contemplam uma faixa histórica de período necessária para subsidiar dados para construção de obras hidráulica e hidrológica e se concentram apenas em fenômenos isolados que ocorrem atualmente. Iniciativas desse tipo são exemplificadas nos estudos de Bernini et al. (2013).

Dessa forma a ausência dessas informações no estado, acaba por obriga-lo a utilizar, como alternativa para a realização de projetos de obras hidráulicas, dados de postos meteorológicos próximos ou de características climatológicas similares a da localidade na qual o projeto é realizado. 
Tal procedimento, entretanto, pode levar a estimativas pouco confiáveis, devido a essa prática apresentar o risco das obras serem subestimadas, trazendo problemas, principalmente, de ordem social, assim como, serem hiperestimadas, onerando os custos das mesmas.

Em vista ao exposto, este estudo objetivou de forma geral analisar os eventos de precipitação máxima extrema das estações pluviométricas inseridas no estado de Rondônia, disponíveis no sítio da Agência Nacional de Águas.

\section{MATERIAL E MÉTODOS}

\section{1 ÁREA DE ESTUDO}

\subsubsection{Localização e Características Gerais}

O Estado de Rondônia (FIGURA 1) localiza-se na Amazônia Ocidental entre os paralelos de $7^{\circ} 58^{\prime}$ e $13^{\circ} 43^{\prime}$ de Latitude Sul e meridianos de $59^{\circ} 50^{\prime}$ e $66^{\circ} 48^{\prime}$ de Longitude Oeste. O estado é composto por 52 municípios, sendo o mais populoso a capital, Porto Velho, que possui 428.527 habitantes (IBGE, 2010).

O estado de Rondônia apresenta altitudes que variam entre 70 e 600 metros, sendo suas principais unidades de relevo: Planícies Amazônicas; Depressões (Amazônia Meridional, Guaporé e Solimões); Planaltos (Amazônia Meridional e dos Parecis); Pantanal do Guaporé. Os tipos de vegetação encontrados na região são as Florestas Ombrófila Aberta, Florestas Ombrófilas Densas (Floresta Amazônica), Florestas Estacionais Semidecidual, Savanas e Vegetação Aluvial, com predominância de Florestas Densas a noroeste do estado (BRASIL, 1978).

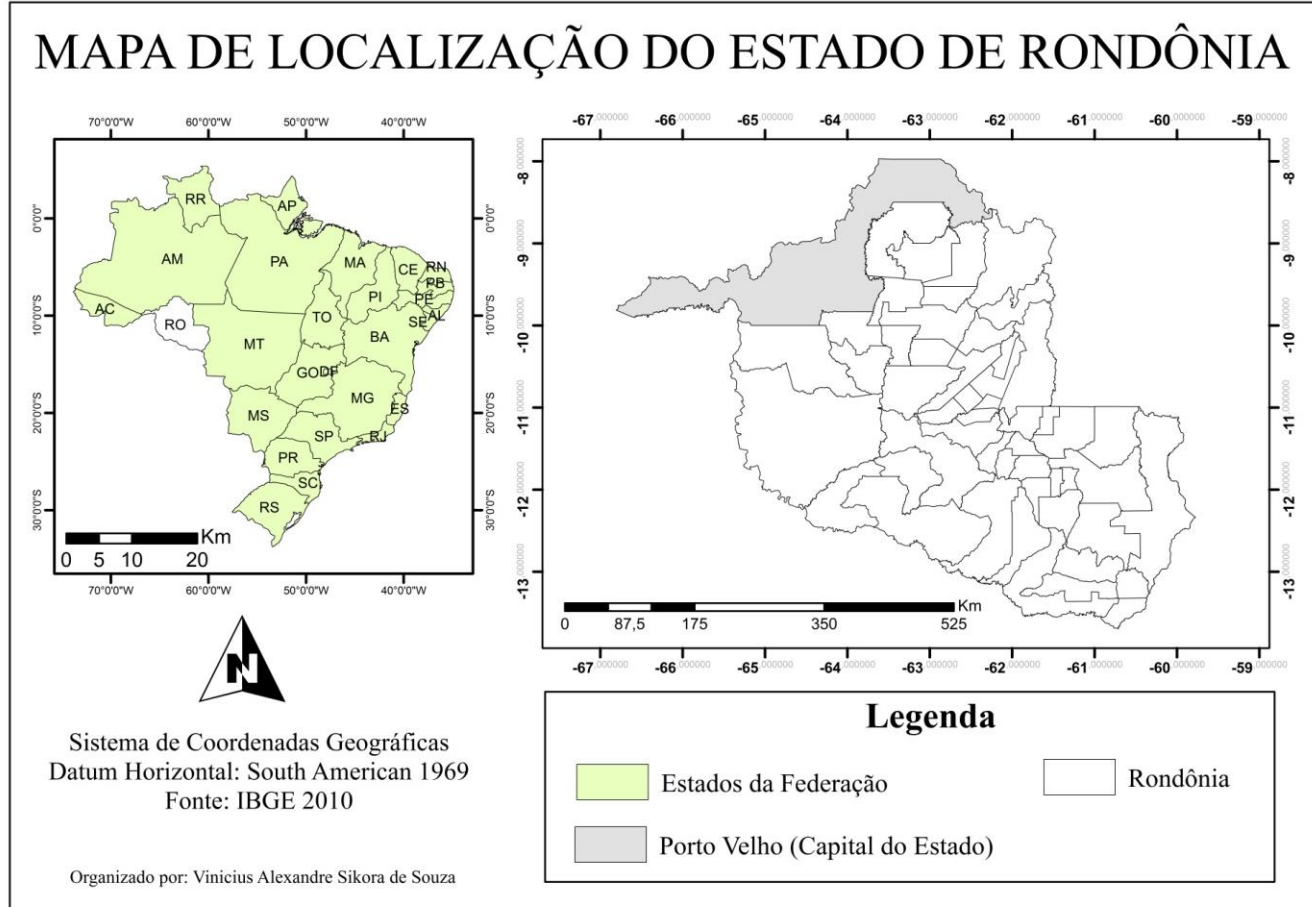

Figura 1 - Localização do estado de Rondônia. 
O estado de Rondônia possui sete bacias hidrográficas principais: Rio Guaporé (59.339,380 km²); Rio Mamoré (22.790,663 km²); Rio Abunã (4.792,210 km²); Rio Madeira $\left(31.422,152 \mathrm{~km}^{2}\right)$; Rio Jamari $\left(29.102,708 \mathrm{~km}^{2}\right)$; Rio Machado $\left(80.630,566 \mathrm{~km}^{2}\right)$; e Rio Roosevelt $\left(15.538,192 \mathrm{~km}^{2}\right)$ (SILVA; ZUFFO, 2003).

\subsubsection{Clima}

Na classificação de Köppen, o clima do estado de Rondônia é caracterizado como AW (tropical-quente e úmido), com média climatológica da temperatura do ar durante o mês mais frio superior a $18{ }^{\circ} \mathrm{C}$ (megatérmico) e um período seco bem definido durante a estação de inverno, quando ocorre no Estado um moderado déficit hídrico com índices pluviométricos inferiores a $50 \mathrm{~mm} / \mathrm{mês}$. (RONDÔNIA, 2009).

A precipitação pluviométrica anual na região central do estado é, em média, acima de $2.000 \mathrm{~mm}$, com umidade relativa do ar média de $82 \%$ e temperatura média anual oscilando de $24^{\circ} \mathrm{C}$ na estação chuvosa a $25^{\circ} \mathrm{C}$ na seca (AGUIAR et al., 2006; WEBLER; AGUIAR; AGUIAR, 2007).

Esta região, segundo a Secretária do Estado de Desenvolvimento Ambiental SEDAM - (2009), não sofre grandes influências da continentalidade, ou seja, maior ou menor distância em relação ao mar.

\subsection{ANÁLISE DOS DADOS}

\subsubsection{Aquisição dos Dados}

Os dados de precipitação utilizados neste estudo foram obtidos por meio do banco de dados disponibilizados pela Agência Nacional de Águas (ANA). Destacase que as informações desse banco vêm sendo utilizadas em vários estudos similares, dentre os quais: Arantes et al. (2009); Butt, Oliveira e Costa (2011); Fietz e Comunell (2006); e Oliveira et al. (2010).

Além disso, outro fator que viabilizou o uso desta fonte de dados ao invés de fontes de geoprocessamento como imagens TRMM ou informações providas do radar meteorológico instalado no estado e operado pelo Sistema de Proteção da Amazônia (Sipam) foi devido a mesma conter dados de períodos mais antigos do que estas citadas, visto que as imagens TRMM encontram-se disponíveis após o ano de 1997; e os radares do Sipam foram instalados no estado em 2003 cobrindo uma área máxima de varredura de até $400 \mathrm{Km}$ de raio, o que não compreende todo o território do estado.

Esse órgão mantém em seus registros dados de precipitação pluviométrica acumulados em períodos de um dia para 93 estações pluviométricas do estado de Rondônia, no entanto, apenas 41 apresentaram um conjunto de dados com uma série temporal igual ou superior a 10 anos, sendo tal característica explicitada no estudo de CETESB (1979, apud FIETZ; COMUNELL, 2006) como requisito para a confecção das equações IDF, as quais são alvo deste estudo. Desta forma, somente os dados dessas 41 estações foram utilizados. 
Na Tabela 1 apresentam-se algumas informações mais detalhadas das estações utilizadas no estudo e, na Figura 2 nota-se a localização das mesmas.

\begin{tabular}{|c|c|c|c|}
\hline Estação & Código & Série (anos) & Meses efetivos \\
\hline 1 & 1360002 & $1983-2010$ & 333 \\
\hline 2 & 1360001 & $1983-2010$ & 336 \\
\hline 3 & 1360000 & $1983-2010$ & 334 \\
\hline 4 & 1264000 & $1983-2010$ & 329 \\
\hline 5 & 1262001 & $1999-2010$ & 139 \\
\hline 6 & 1262000 & $1980-2010$ & 352 \\
\hline 7 & 1261001 & $1999-2010$ & 130 \\
\hline 8 & 1261000 & $1983-2006$ & 260 \\
\hline 9 & 1260001 & $1967-2003$ & 337 \\
\hline 10 & 1164001 & $1983-2002$ & 229 \\
\hline 11 & 1164000 & $1976-1989$ & 167 \\
\hline 12 & 1161003 & $1999-2010$ & 131 \\
\hline 13 & 1161002 & $1983-2010$ & 315 \\
\hline 14 & 1161001 & $1980-2010$ & 372 \\
\hline 15 & 1161000 & $1977-2010$ & 395 \\
\hline 16 & 1160002 & $1982-2010$ & 334 \\
\hline 17 & 1160000 & $1977-2010$ & 393 \\
\hline 18 & 1065002 & $1972-2010$ & 451 \\
\hline 19 & 1063001 & $1980-2010$ & 354 \\
\hline 20 & 1063000 & $1978-2010$ & 358 \\
\hline 21 & 1062004 & $1986-2010$ & 285 \\
\hline 22 & 1062003 & $1983-2010$ & 324 \\
\hline 23 & 1062002 & $1978-2010$ & 383 \\
\hline 24 & 1062001 & $1977-2010$ & 399 \\
\hline 25 & 1061003 & $1987-2010$ & 285 \\
\hline 26 & 1061001 & $1975-1997$ & 262 \\
\hline 27 & 966001 & $1982-2010$ & 316 \\
\hline 28 & 966000 & $1977-2010$ & 404 \\
\hline 29 & 965001 & $1976-2010$ & 377 \\
\hline 30 & 964001 & $1978-2002$ & 290 \\
\hline 31 & 963009 & $1997-2010$ & 162 \\
\hline 32 & 963006 & $1983-2001$ & 223 \\
\hline 33 & 963004 & $1980-2010$ & 366 \\
\hline 34 & 963001 & $1977-2010$ & 387 \\
\hline 35 & 963000 & $1975-2010$ & 420 \\
\hline 36 & 962001 & $1981-2007$ & 308 \\
\hline 37 & 962000 & $1978-2010$ & 378 \\
\hline 38 & 961003 & $1987-2009$ & 273 \\
\hline 39 & 863003 & $1975-2002$ & 297 \\
\hline 40 & 863000 & $1961-2007$ & 564 \\
\hline 41 & 862000 & $1977-2010$ & 385 \\
\hline
\end{tabular}

Tabela 1 - Dados das estações pluviométricas amostradas. 
Nas análises dos dados obteve-se primeiramente para a série histórica de cada estação pluviométrica analisada, a altura máxima de chuva de "um dia" de cada ano, constituindo, dessa forma, a série de chuvas máximas anuais.

E, a seguir os dados foram organizados em ordem decrescente, sendo a média aritmética e o desvio-padrão das amostras calculados. Tal procedimento possibilitou analisar estatisticamente a probabilidade e o período de retorno das chuvas intensas, através do método da distribuição de Gumbel, o qual é amplamente utilizado na modelagem desse fenômeno (BACK, 2001; NAGHETTINI; PINTO, 2007; TUCCI, 2009).

A variável reduzida de Gumbel (y) foi obtida pela Equação 1, como preconizado por Gumbel (2004).

$y=\frac{s_{y}}{s_{x}}\left[x_{i}-\left(x_{m}-s_{x} \frac{y_{m}}{s_{y}}\right)\right]$

Onde: $s_{x}$ - Desvio-padrão da série; $x_{i}$ - Valor de um elemento da amostra; $x_{m}$ Média da amostra da série anual finita de $n$ valores; $\mathrm{s}_{\mathrm{y}}$ - Desvio-padrão, valor tabelado; e $y_{m}$ - Média da variável reduzida ( $y$ ), tabelada em função do número de dados da amostra.

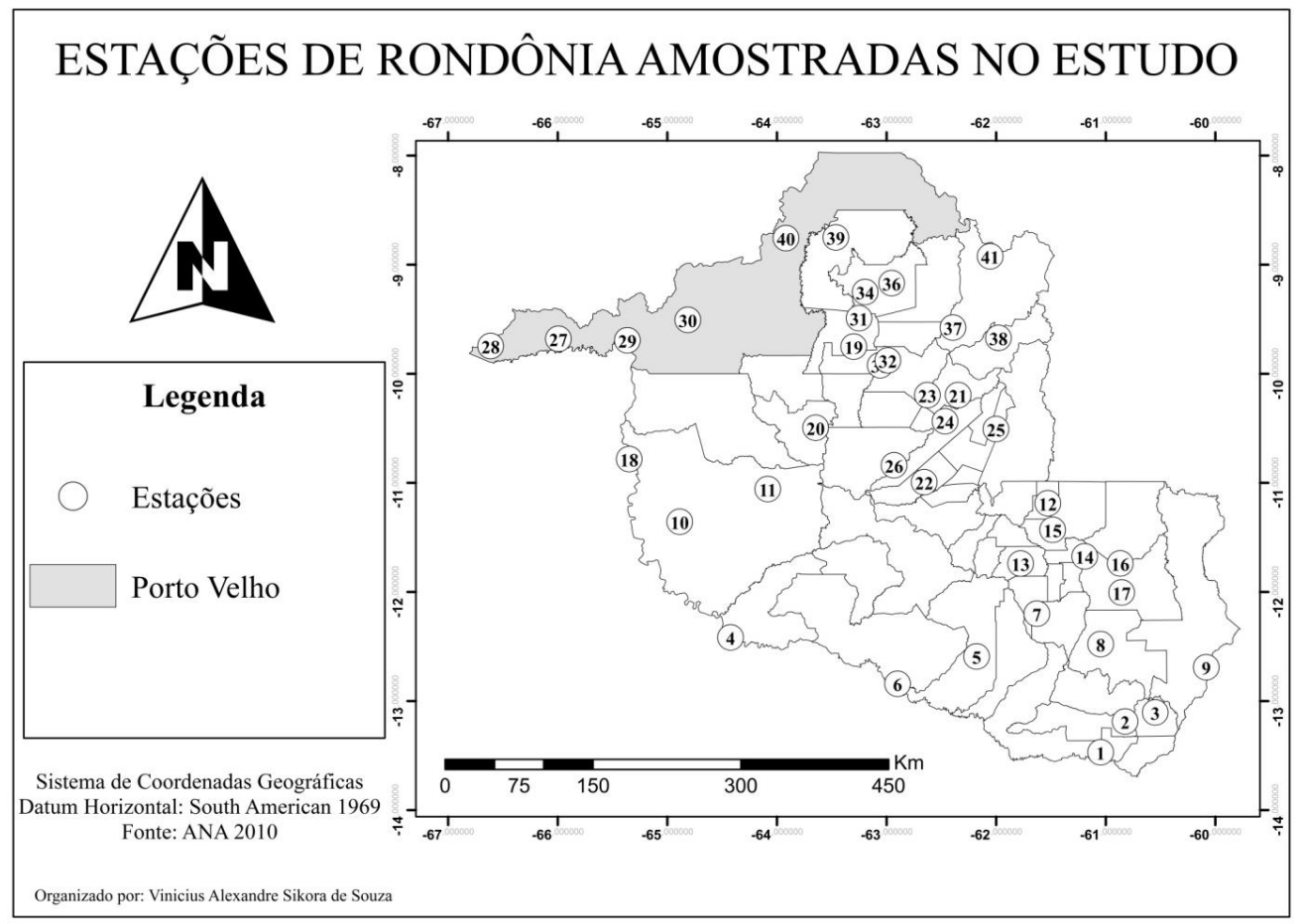

Figura 2 - Localização das estações pluviométricas do estado de Rondônia utilizadas neste estudo.

O período de retorno ( $\mathrm{Tr}$ ), definido como o intervalo médio, em anos, em que um valor qualquer de chuva é igualado ou superado, pelo menos uma vez é estimado pela Equação 2. Sendo essa expressão, função da base dos logaritmos neperianos (e). 
$\operatorname{Tr}=\frac{1}{1-e^{-e^{-y}}}$

Após esse procedimento, os dados posteriormente foram plotados em um gráfico que apresentasse as mesmas características do papel logprobabilístico, conhecido também como papel de Gumbel, ou seja, os pontos correspondentes às alturas máximas de chuva ( $p$ ) ficaram na ordenada, em escala aritmética, e o período de retorno, em anos, correspondente na abscissa, em escala logarítmica-probabilística.

Após essa ação ajustou-se uma reta para os dados desse gráfico, que compreendeu a amplitude dos dados analisados, pois as mesmas apresentaram coeficiente de ajuste $\left(r^{2}\right)$ variando de $89 \%$ a aproximadamente $100 \%$, como se observa na Tabela 2.

Assim, foi possível estimar para diversos períodos de retorno as precipitações máximas com duração de "um dia".

\begin{tabular}{ccc}
\hline Código & Estação & $\mathbf{r}^{\mathbf{2}}$ \\
\hline 1360002 & 1 & 0,901 \\
1360001 & 2 & 0,967 \\
1360000 & 3 & 0,962 \\
1264000 & 4 & 0,970 \\
1262001 & 5 & 0,968 \\
\hline 1262000 & 6 & 0,922 \\
1261001 & 7 & 0,984 \\
1261000 & 8 & 0,987 \\
1260001 & 9 & 0,978 \\
1164001 & 10 & 0,929 \\
1164000 & 11 & 0,950 \\
1161003 & 12 & 0,926 \\
1161002 & 13 & 0,950 \\
1161001 & 14 & 0,982 \\
1161000 & 15 & 0,938 \\
\hline 1160002 & 16 & 0,976 \\
1160000 & 17 & 0,951 \\
\hline 1065002 & 18 & 0,982 \\
1063001 & 19 & 0,974 \\
\hline 1063000 & 20 & 0,991 \\
1062004 & 21 & 0,980 \\
\hline
\end{tabular}

\begin{tabular}{ccc}
\hline Código & Estação & $\mathbf{r}^{\mathbf{2}}$ \\
\hline 1062003 & 22 & 0,896 \\
1062002 & 23 & 0,941 \\
1062001 & 24 & 0,964 \\
1061003 & 25 & 0,918 \\
1061001 & 26 & 0,954 \\
966001 & 27 & 0,931 \\
966000 & 28 & 0,943 \\
965001 & 29 & 0,988 \\
964001 & 30 & 0,961 \\
963009 & 31 & 0,896 \\
963006 & 32 & 0,894 \\
963004 & 33 & 0,967 \\
963001 & 34 & 0,960 \\
963000 & 35 & 0,971 \\
962001 & 36 & 0,962 \\
962000 & 37 & 0,970 \\
961003 & 38 & 0,954 \\
863003 & 39 & 0,963 \\
863000 & 40 & 0,995 \\
862000 & 41 & 0,919 \\
- & - & - \\
\hline
\end{tabular}

Tabela 2 - Coeficientes de ajuste das equações estimadas para os dados das estações analisada

Depois de obtidas as alturas das chuvas para os períodos de 2 a 100 anos, estimou-se as prováveis intensidades máximas médias para todas as durações de chuva de 5 minutos a 24 horas, por meio da desagregação de chuva diária, sendo para tal procedimento utilizado os quocientes das relações médias a nível nacional (TABELA 3), obtidos por CETESB (1979), explicitado em Tucci (2009). 


\begin{tabular}{ll}
\hline Relação & Quociente \\
\hline $5 \mathrm{~min} / 30 \mathrm{~min}$ & 0,34 \\
$10 \mathrm{~min} / 30 \mathrm{~min}$ & 0,54 \\
$15 \mathrm{~min} / 30 \mathrm{~min}$ & 0,70 \\
\hline $20 \mathrm{~min} / 30 \mathrm{~min}$ & 0,81 \\
$25 \mathrm{~min} / 30 \mathrm{~min}$ & 0,91 \\
30min/1h & 0,74 \\
$1 \mathrm{~h} / 24 \mathrm{~h}$ & 0,42 \\
$6 \mathrm{~h} / 24 \mathrm{~h}$ & 0,72 \\
$8 \mathrm{~h} / 24 \mathrm{~h}$ & 0,78 \\
$10 \mathrm{~h} / 24 \mathrm{~h}$ & 0,82 \\
$12 / 24 \mathrm{~h}$ & 0,85 \\
24h/1dia & 1,14 \\
\hline
\end{tabular}

Tabela 3 - Quocientes a nível nacional das relações entre durações. Fonte: Tucci (2009)

\subsection{AFERIMENTO DOS EVENTOS PLUVIOMÉTRICOS MÁXIMOS MÉDIOS PARA AS BACIAS HIDROGRÁFICAS}

Na determinação da pluviosidade extrema média para cada uma das sete bacias hidrográficas do estado de Rondônia foram utilizadas às técnicas da média aritmética dos polígonos de Thiessen e das isoietas.

O cálculo pela média aritmética se realizou primeiramente pela obtenção dos dados de intensidade para cada período de retorno e duração das estações pluviométricas presentes na bacia, sendo que posteriormente utilizou-se tais dados na Equação 3, em substituição da variável altura precipitada, para que, desta forma, o resultado correspondesse a uma intensidade máxima média da bacia.

$P_{m}=\frac{1}{n} \sum_{i=n}^{n} P i$

Onde:

$P_{m}$ - Altura pluviométrica média $(\mathrm{mm})$ precipitada sobre uma determinada área;

$P_{i}$ - Precipitação no enésimo pluviômetro $(\mathrm{mm})$;

n - Número total de pluviômetros utilizados no cálculo.

Na determinação da chuva máxima pelo método dos polígonos de Thiessen gerou, primeiramente, o elemento geométrico correspondente a intensidade de cada posto pluviométrico para uma duração e tempo de retorno específico. A criação das áreas foi realizada por meio do software Quantum Gis ${ }^{\circ}$ (SHERMAN et al., 2011), onde primeiramente converteu-se as coordenadas geográficas das estações pluviométricas amostradas, presentes numa tabela, para um arquivo em formato shape file (.shp), sendo esse posteriormente utilizado para a criação dos polígonos de influência ao selecionar na barra de menus do programa a opção "diagrama de Voronoi". Após esse procedimento, interseccionou-se o diagrama gerado com o arquivo vetorial do estado de Rondônia, possibilitando dessa forma, gerar e identificar as áreas de influência das estações 
pluviométricas do estado. Posteriormente, de posse desses dados, aplicou-se os mesmos na Equação 4, no lugar da altura precipitada.

$P_{m}=\frac{\sum_{i=1}^{n}\left(P_{i} A_{i}\right)}{\sum_{i=1}^{n} A_{i}}$

Em que:

$A_{i}$ - área de influência $\left(m^{2}\right)$ de cada posto pluviométrico.

Ao que concerne o emprego das isoietas, essas foram geradas, no software

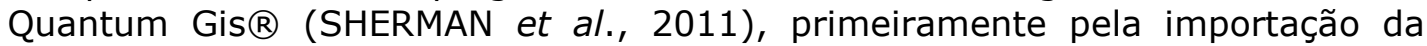
tabela de dados das intensidades das precipitações extremas em seus períodos de retorno e duração específicos, incluindo as localizações geográficas das estações, sendo a importação realizada com o plugin de "texto delimitado".

Para limitar a análise para a área abrangida pelos pluviômetros, criou-se uma forma convexa simples mínima, através da seleção do item "forma(s) convexa(s)" no sub-menu "Ferramentas de Geoprocessamento" do menu "Vetor". A fim de expandir a análise para a extensão de todo o estado gerou-se um "Buffer" da forma criada, sendo essa opção localizada também no sub-menu "Ferramentas de Geoprocessamento".

Após essas etapas, a geometria resultante sofreu uma intersecção com o shape file do contorno de Rondônia. Como procedimento posterior a criação das isoietas, importou-se a forma geométrica criada nos passos anteriores, juntamente com o vetor dos pontos das estações para uma extensão denominada "GRASS" no próprio software, por meio do módulo "v.in.ogr.qgis".

Realizada tais ações, converteu-se a geometria interseccionada para um "raster" utilizando o comando "v.to.rast", para que o mesmo pudesse ser usado como uma máscara. Posteriormente, foi utilizado o módulo "r.mask", com o objetivo de forçar a aproximação entre o raster, recém gerado, e o vetor das estações pluviométricas.

Na criação das grades interpoladas das intensidades das precipitações extremas utilizou-se o "v.surf.rst", sendo selecionado como campo de atributo para fazer a interpolação da coluna que contivesse a intensidade de precipitação, com o $\mathrm{Tr}$ e t de interesse. Como procedimento final na geração das grades, elas foram convertidas em curvas por meio do comando "r.contour".

De posse das isoietas, extraiu-se os dados pertinentes de serem aplicados na Equação 5, para o cálculo da média, frisando que novamente a altura precipitada foi substituída pela intensidade.

$P_{m}=\frac{1}{A}\left(\frac{P_{i}+P_{i+1}}{2}\right) \sum A_{\mathrm{i}, i+1}$

Onde: $A$ - é a área total $\left(\mathrm{m}^{2}\right) ;$ e $\mathrm{P}_{\mathrm{i}+1}$ - precipitação pluviométrica $(\mathrm{mm})$ do enésimo pluviômetro adjacente. 
Ressalta-se que posteriormente, ao obter os dados de intensidades médias, para cada bacia hidrográfica de Rondônia em cada um dos métodos descritos acima, esses foram submetidos ao teste estatístico não paramétrico de KruskalWallis (K-W) com $\alpha$ de 0,001 , devido a este ser o menor nível de confiança, que resultaria num menor erro do tipo $\mathrm{I}$, com que o software trabalha, sendo o mesmo realizado pelo Graphpad Prism ${ }^{\circledR} 5.0$ demo (GRAPHPAD SOFTWARE INC., 2007).

Frisa-se que o critério de decisão utilizado nesse teste foi o valor-p, sendo o mesmo maior que $\alpha$ não rejeitar-se-ia a hipótese nula formulada para o teste, a qual consistia na afirmação da inexistência de diferenças estatística para os valores de intensidade de precipitação média das bacias hidrográficas obtidos pelas técnicas da média aritmética, dos polígonos de Thiessen e das isoietas. Em contraposição se o valor-p apresenta-se em uma magnitude inferior ao $\alpha$ estabelecido, essa característica denotaria que a hipótese nula deve ser rejeitada em função da hipótese alternativa, pois existem diferenças estatísticas entre os resultados fornecidos pelas técnicas utilizadas.

Destaca-se ainda que o teste de Kruskal-Wallis foi complementado pelo teste

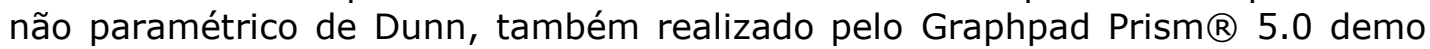
(GRAPHPAD SOFTWARE INC., 2007), a fim de averiguar em qual das técnicas residiria as discrepâncias, caso houvesse, que forçaria a rejeição da hipótese nula.

\section{RESULTADOS E DISCUSSÃO}

Os eventos pluviométricos extremos registrados nas séries históricas das estações amostradas neste estudo estão evidenciados na Tabela 4, sendo apresentadas, na mesma, as intensidades (i) dos eventos máximos e mínimos anuais, com seus respectivos anos de ocorrência (AO) e períodos de retorno (Tr). Na referida tabela também estão contidas as médias dos eventos máximos e o desvio padrão para esse fenômeno.

De forma geral, a média das chuvas máximas de "um dia", no estado de Rondônia encontra-se variando de aproximadamente 71,3 a 173,5 mm/dia, sendo ambas as médias presentes em postos localizados no município de Porto Velho.

Esse alto índice de precipitação observado em todas as séries históricas das estações amostradas é característico dos aspectos climáticas da região, pois segundo Rondônia (2009), a média anual da precipitação pluvial no Estado de Rondônia varia entre 1.400 a 2.600 mm/ano. 


\begin{tabular}{|c|c|c|c|c|c|c|c|c|}
\hline \multirow[b]{2}{*}{ Estação } & \multicolumn{3}{|c|}{ Máximo } & \multicolumn{3}{|c|}{ Mínimo } & \multirow{2}{*}{$\begin{array}{l}\text { Média } \\
(\mathrm{mm} / \mathrm{d})\end{array}$} & \multirow{2}{*}{$\begin{array}{l}\text { Desvio } \\
\text { Padrão } \\
(\mathrm{mm} / \mathrm{d})\end{array}$} \\
\hline & $\begin{array}{c}\mathrm{i} \\
(\mathrm{mm} / \mathrm{d})\end{array}$ & $\begin{array}{c}\mathrm{Tr} \\
\text { (anos) }\end{array}$ & $\begin{array}{c}\text { AO } \\
\text { (ano) }\end{array}$ & $\begin{array}{c}\mathbf{i} \\
(\mathrm{mm} / \mathrm{d})\end{array}$ & $\begin{array}{c}\mathrm{Tr} \\
\text { (anos) }\end{array}$ & $\begin{array}{c}\text { AO } \\
\text { (ano) }\end{array}$ & & \\
\hline 1 & 227,4 & 55,906 & 2008 & 9,7 & 1,009 & 2002 & 90,860 & 43,338 \\
\hline 2 & 176,6 & 19,551 & 1996 & 42 & 1,039 & 1986 & 98,025 & 35,978 \\
\hline 3 & 165 & 23,387 & 1992 & 52,5 & 1,028 & 1989 & 98,728 & 28,199 \\
\hline 4 & 135 & 12,037 & 1998 & 28,9 & 1,010 & 2004 & 83,885 & 29,553 \\
\hline 5 & 123,4 & 9,455 & 2010 & 48,5 & 1,034 & 2000 & 86,391 & 21,562 \\
\hline 6 & 126,4 & 13,158 & 1998 & 39,5 & 1,000 & 1990 & 89,019 & 20,849 \\
\hline 7 & 110,5 & 6,975 & 2007 & 57,4 & 1,101 & 2000 & 84,041 & 19,087 \\
\hline 8 & 144 & 16,918 & 1985 & 48 & 1,177 & 1994 & 80,559 & 30,037 \\
\hline 9 & 195,5 & 128,250 & 1981 & 41,4 & 1,135 & 1990 & 76,712 & 29,869 \\
\hline 10 & 144,8 & 23,254 & 1992 & 10 & 1,005 & 1998 & 71,578 & 29,726 \\
\hline 11 & 95 & 10,966 & 1986 & 56 & 1,023 & 1985 & 75,416 & 10,443 \\
\hline 12 & 109 & 12,339 & 2006 & 52,4 & 1,010 & 1999 & 81,058 & 13,965 \\
\hline 13 & 141 & 13,606 & $\begin{array}{l}1991 \\
1992\end{array}$ & 43,6 & 1,002 & 2004 & 95,432 & 24,695 \\
\hline 14 & 131,2 & 13,919 & 2003 & 62,4 & 1,071 & 1986 & 91,738 & 21,385 \\
\hline 15 & 215,3 & 66,309 & 1990 & 21,2 & 1,000 & 1989 & 100,161 & 35,531 \\
\hline 16 & 184,2 & 110,170 & 1997 & 52,2 & 1,090 & 1982 & 86,251 & 26,088 \\
\hline 17 & 173,4 & 21,306 & 1998 & 35,4 & 1,004 & 1989 & 100,438 & 32,906 \\
\hline 18 & 222 & 52,721 & $\begin{array}{l}1987 \\
2003\end{array}$ & 41,2 & 1,061 & 1990 & 98,607 & 41,080 \\
\hline 19 & 167,4 & 20,378 & 1996 & 58 & 1,035 & 1995 & 103,537 & 28,848 \\
\hline 20 & 423,4 & 285,350 & 2002 & 31,8 & 1,184 & 1992 & 104,068 & 69,667 \\
\hline 21 & 134,2 & 13,676 & 1998 & 59,5 & 1,051 & 2008 & 92,650 & 22,037 \\
\hline 22 & 115,4 & 18,010 & 1987 & 32,7 & 1,000 & 1994 & 78,817 & 17,357 \\
\hline 23 & 150,6 & 33,308 & 1979 & 60 & 1,007 & 1997 & 97,924 & 20,033 \\
\hline 24 & 212,8 & 147,970 & 1983 & 53,3 & 1,045 & 2010 & 97,008 & 29,259 \\
\hline 25 & 140,8 & 19,844 & 2005 & 65 & 1,005 & $\begin{array}{l}1989 \\
2003\end{array}$ & 100,921 & 17,713 \\
\hline 26 & 170 & 31,259 & 1991 & 58,7 & 1,035 & 1996 & 100,556 & 25,907 \\
\hline 27 & 101,2 & 8,756 & 1988 & 30,1 & 1,000 & 2004 & 74,939 & 18,414 \\
\hline 28 & 190 & 97,333 & 1993 & 46 & 1,005 & 1990 & 96,867 & 25,988 \\
\hline 29 & 464,8 & 536,010 & 2007 & 28 & 1,280 & 1990 & 90,387 & 73,169 \\
\hline 30 & 151 & 13,805 & 1993 & 9,4 & 1,057 & 1997 & 71,341 & 42,048 \\
\hline 31 & 135,7 & 8,764 & 2003 & 27 & 1,001 & 1997 & 92,128 & 27,478 \\
\hline
\end{tabular}


(Continuação) Tabela 4 - Eventos extremos das estações amostradas

\begin{tabular}{|c|c|c|c|c|c|c|c|c|}
\hline \multirow[b]{2}{*}{ Estação } & \multicolumn{3}{|c|}{ Máximo } & \multicolumn{3}{|c|}{ Mínimo } & \multirow{2}{*}{$\begin{array}{l}\text { Média } \\
(\mathrm{mm} / \mathrm{d})\end{array}$} & \multirow{2}{*}{$\begin{array}{r}\text { Desvio } \\
\text { Padrão } \\
(\mathrm{mm} / \mathrm{d}) \\
\end{array}$} \\
\hline & $\begin{array}{c}\mathbf{i} \\
(\mathrm{mm} / \mathrm{d})\end{array}$ & $\begin{array}{c}\mathrm{Tr} \\
\text { (anos) }\end{array}$ & $\begin{array}{c}\text { AO } \\
\text { (ano) }\end{array}$ & $\begin{array}{c}\mathbf{i} \\
(\mathrm{mm} / \mathrm{d})\end{array}$ & $\begin{array}{c}\mathrm{Tr} \\
\text { (anos) }\end{array}$ & $\begin{array}{c}\text { AO } \\
\text { (ano) }\end{array}$ & & \\
\hline 32 & 147,7 & 8,271 & 1996 & 14,3 & 1,000 & 2000 & 98,794 & 33,839 \\
\hline 33 & 165,2 & 33,474 & 1996 & 59,8 & 1,027 & 1980 & 99,977 & 24,600 \\
\hline 34 & 185 & 67,780 & 1984 & 64 & 1,032 & 2002 & 103,567 & 24,978 \\
\hline 35 & 201,2 & 39,063 & 1990 & 63,5 & 1,043 & 2008 & 112,114 & 32,391 \\
\hline 36 & 218 & 38,680 & 1991 & 53,2 & 1,019 & 1986 & 115,855 & 36,152 \\
\hline 37 & 150 & 24,404 & 1978 & 69,3 & 1,060 & 2007 & 99,606 & 21,172 \\
\hline 38 & 150,2 & 16,101 & 2005 & 47 & 1,015 & 1992 & 95,300 & 26,429 \\
\hline 39 & 133,2 & 19,669 & 1992 & 60,4 & 1,058 & 1993 & 89,147 & 19,146 \\
\hline 40 & 665,3 & 77,784 & 2001 & 43,2 & 1,257 & 1989 & 173,542 & 149,014 \\
\hline 41 & 137,8 & 27,204 & 1981 & 40,8 & 1,000 & 1991 & 88,088 & 20,381 \\
\hline
\end{tabular}

Tabela 4 - Eventos extremos das estações amostradas.

Observando a Tabela 4 pode se verificar que a maior altura de chuva intensa encontrada em todas as séries históricas foi de $665,3 \mathrm{~mm} / \mathrm{dia}$ em Porto Velho, no ano de 2001. Porém, o período de retorno de um fenômeno de mesma magnitude ou superior incida novamente em tal localidade constitui-se em apenas 77,784 anos. Dessa forma, observa-se que na área na qual está localizada tal pluviômetro, apresenta um alto índice de chuvas extremas, fato que pode ser observado pelo período de retorno.

O evento com o maior período de recorrência observado na Tabela 4 foi no município de Porto Velho com 536,010 anos com uma magnitude de 464,8 $\mathrm{mm} / \mathrm{dia}$, sendo esse observado no ano de 2007.

Ressalta-se que a ocorrência desse fenômeno foi captado até mesmo pelos radares hidroestimadores de precipitação do Centro de Previsão de Tempo e Estudos Climáticos do Instituto Nacional de Pesquisas Espaciais (CPTEC/INPE), dado o núcleo da tempestade, a qual apresentou deslocamento de noroeste/sudeste, sendo as Zonas Norte e Oeste de Porto Velho as mais afetadas pelo temporal (DE OLHO NO TEMPO, 2011).

Em análise a Tabela 4 nota-se a ocorrência de chuvas intensas máximas em algumas estações pluviométricas no mesmo período de acontecimento, sendo os anos de 1992, 1991, 1998, 1996 e 2003, os que possuem mais repetições de intensidades extremas máximas.

Portanto, nesses períodos fica evidente a atuação de algum fenômeno meteorológico, como o La Niña que segundo Cutrim, Molion e Nechet (2000) ocasiona anomalias positivas de precipitação na região amazônica. Não obstante, esse mesmo fenômeno meteorológico foi apontado por Bergamaschi 
et al. (2004), como responsável pela ocorrência de precipitações abaixo da média histórica na região sul do Brasil.

Ao que tange os eventos extremos mínimos anuais esses mostram a existência de períodos mais secos em determinadas regiões, pois se observa que as ocorrências encontram-se muito abaixo das médias das mesmas localidades, o que pode denotar a presença de algum fenômeno climático que interferiu de forma expressiva na chuva de tais anos, como o El Niño, destacado no estudo de Silva, Saraiva e Silva (2010), como fator principal nos casos das secas registradas na região amazônica, nos períodos de 1925-1926, 1968-1969 e 1997-1998.

Nesse sentido, Santos e Buchmann (2010) relatam que tal fenômeno é caracterizado pelo aquecimento das águas superficiais do oceano Pacífico Equatorial (porção centro-oeste) e pelo enfraquecimento dos ventos alísios de leste. Assim, o mesmo pode provocar alterações climáticas e prejuízos financeiros em várias partes do globo.

Portanto, as constatações explicitadas acima acordam com os resultados de Grimm e Tedeschi (2004), que ao analisarem dados diários de precipitação de 2714 estações meteorológicas de todo Brasil, provenientes da ANA, durante o período 1956-2002, verificou que na Região Norte do país, há um maior acréscimo de eventos extremos durante La Niña e diminuição dos mesmos durante El Niño, sendo, no entanto, o comportamento dos mesmos sem muita simetria, pois o La Niña provoca aumentos na precipitação com mais frequência que o El Niño gera redução dessa variável.

Frisa-se que as discrepâncias nas alturas extremas máximas e mínimas justificam os altos valores encontrados para os desvios padrões da série. Essa alta dispersão dos dados de precipitação, indicada pelo desvio padrão, também foram mostradas por Mehl et al. (2001), que ao caracterizar os padrões de chuvas ocorrentes em Santa Maria - RS, observaram desvios padrões acima de $30 \mathrm{~mm}$ em precipitações com duração de $10 \mathrm{~min}$.

Outro fator notório é a inexistência de um padrão entre as intensidades extremas máximas e mínimas para as diversas localidades onde se encontram os pluviômetros analisados, sendo dois os elementos responsáveis por esta característica: as séries históricas que contemplam períodos diferentes, como se observa na Tabela 2; e os fenômenos meteorológicos presentes no estado que atuam na dinâmica do regime pluvial, tais como as altas convecções diurnas, a Alta da Bolívia, a Zona de Convergência Intertropical e as Linhas de Instabilidade (GAMA, 2003).

A Figura 3 exibe a distribuição das chuvas extremas mais intensas com maior recorrência em Rondônia, sendo essas com duração de 5 min e tempo de retorno de 2 anos, na forma de isoietas. Destaca-se que precipitações com essas características são apontadas por Brandão, Rodrigues e Costa (2001), como chuvas de alto fator erosivo, que podem acarretar danos de ordem ambiental e econômico. Além disso, ainda está presente nessa ilustração as características de uso e ocupação do solo do estado, segundo os dados colhidos por RADAM (BRASIL, 1978). 
É possível observar na Figura 3, que as chuvas extremas com os atributos descritos acima, aumentam sua intensidade ao se aproximarem da região mais ao norte do estado, esse fato pode ocorrer devido à maior proximidade com a linha do equador, onde se encontra presente uma zona de baixa pressão denominada de Zona de Convergência Intertropical (ZCIT).

Segundo Xavier et al. (2000), esse fenômeno propicia a formação de nuvens cúmulo-nimbos, sendo tal fator responsável por chuvas intensas sobre regiões tropicais como o Brasil.

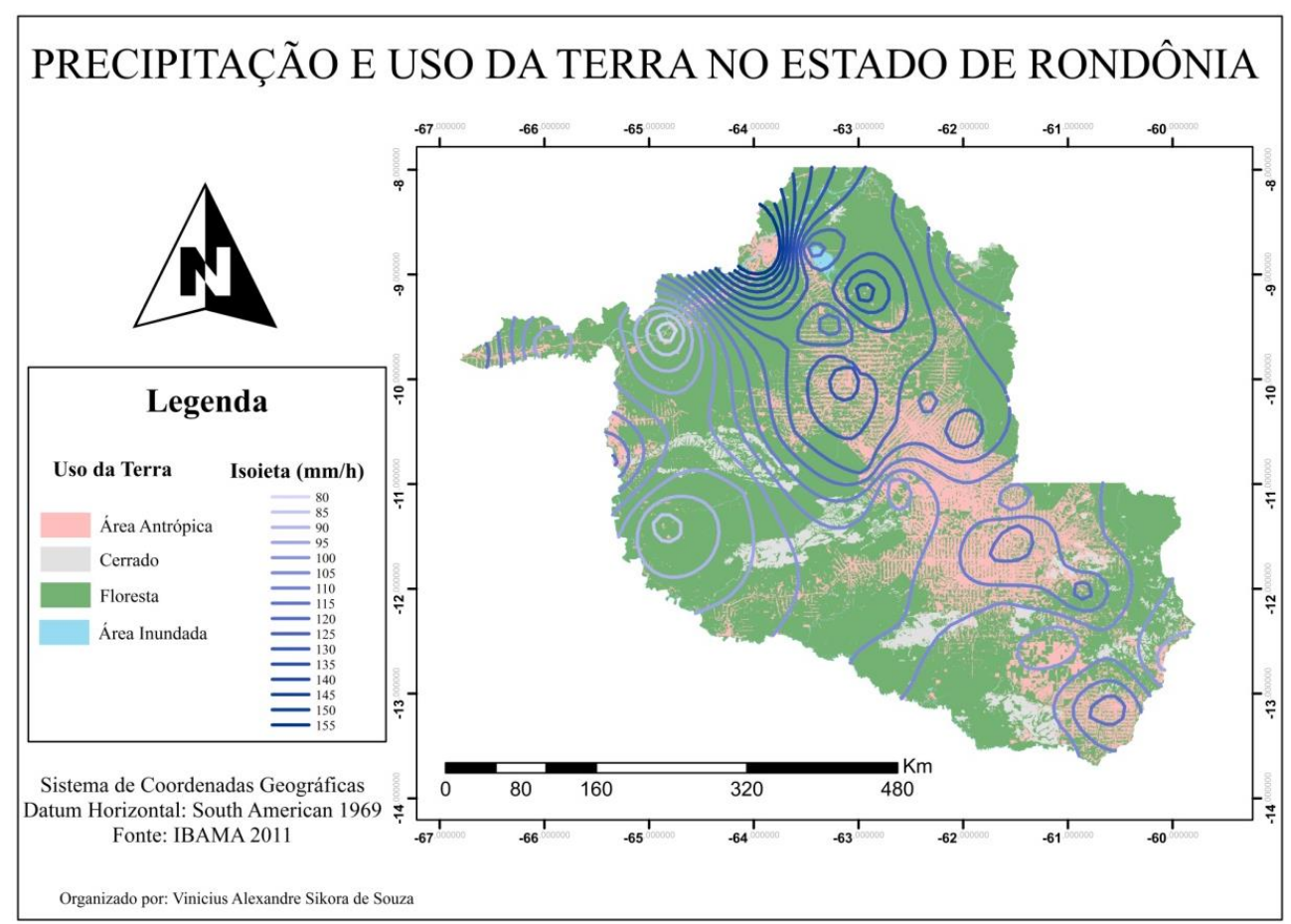

Figura 3 - Relação da precipitação máxima e uso e ocupação da terra no estado de Rondônia.

Ao relacionar o uso e ocupação do solo com as precipitações, não se observa uma relação clara entre um uso predominante do solo e a minimização ou maximização dos eventos pluviométricos extremos.

A explicação de tal fato pode residir na falta de compreensão do ciclo hidrológico da Região Amazônica quanto à influência do desmatamento, pois Cohen et al. (2007) explicita a falta de consenso, na utilização de Modelos de Circulação Geral (MCG), quanto ao desmatamento da região amazônica provocar uma diminuição generalizada na precipitação desta mesma região.

Todavia ao examinar a região sudeste de Rondônia (FIGURA 3) nota-se uma leve redução na intensidade da chuva, o que pode ser gerado devido à presença de vários núcleos urbanos nessa região.

Esse fato acorda com o estudo de Werth e Avissar (2002), onde ao realizarem seis simulações climáticas, os mesmos observaram fortes reduções da

$$
\text { Ano } 10 \text { - Vol. } 14 \text { - JAN/JUL } 2014
$$


precipitação, evapotranspiração e nebulosidade com o desmatamento na Amazônia. Sendo que, segundo os autores supracitados, tais mudanças são detectáveis em todo o planeta.

Assim, observa-se que a transformação das áreas florestadas em núcleos urbanizados possam influir na dinâmica de distribuição de chuvas. Como presume Nobre et al. (2004, apud COHEN et al., 2007), alterações dos ciclos da água, energia solar, carbono e nutrientes, resultantes da mudança no uso da terra na região amazônica podem provocar consequências climáticas e ambientais em escalas local, regional e global.

Nesse contexto, o trabalho de Santos Neto, Moraes e Nóbrega (2010) aborda um notável decréscimo nos valores médios decadais da precipitação nesta mesma área, ao analisarem os impactos da ação antrópica na Região central de Rondônia, utilizando para tal uma série histórica de chuvas nos períodos de 1951 a 2008.

A influência do desmatamento nas precipitações do estado de Rondônia também foi observada por Butt, Oliveira e Costa (2011), os quais destacam a existência de uma mudança acentuada no tempo de início da estação chuvosa do estado, projetando atrasos de 18 dias para os próximos 30 anos, caso as características de mudança do uso do solo permaneçam.

A Tabela 5 fornece os dados das intensidades de precipitações máximas médias para as sete bacias hidrográficas do estado de Rondônia, sendo que esses eventos possuem as mesmas características da Figura 3, duração de 5 min e tempo de retorno de 2 anos.

\begin{tabular}{cccc}
\hline Bacia Hidrográfica & \multicolumn{3}{c}{ Intensidade Média (mm/h) } \\
\cline { 2 - 4 } & M.A. & Isoietas & P.T. \\
\hline $\begin{array}{c}\text { Bacia Hidrográfica do Rio } \\
\text { Mamoré }\end{array}$ & 107,329 & 103,728 & 107,176 \\
\hline $\begin{array}{c}\text { Bacia Hidrográfica do Rio } \\
\text { Abunã }\end{array}$ & 98,103 & 95,540 & 95,732 \\
\hline $\begin{array}{c}\text { Bacia Hidrográfica do Rio } \\
\text { Madeira }\end{array}$ & 104,170 & 101,476 & 113,624 \\
Bacia Hidrográfica do Rio \\
$\begin{array}{c}\text { Jamari } \\
\text { Bacia Hidrográfica do Rio } \\
\text { Machado }\end{array}$ & 120,390 & 124,634 & 110,864 \\
\hline $\begin{array}{c}\text { Bacia Hidrográfica do Rio } \\
\text { Roosevelt }\end{array}$ & 114,567 & 113,121 & 114,363 \\
\hline
\end{tabular}

Tabela 5 - Intensidades máximas médias para as Bacias Hidrográficas de Rondônia, calculadas pelas metodologias: Media Aritmética (M. A.), Isoietas e Polígonos de Thiessen (P. T.).

Ao relacionar os resultados de precipitação extrema média das Bacias Hidrográficas de Rondônia, obtidas pelos métodos de Média Aritmética (M. A.), Polígonos de Thiessen (P. T.) e Isoietas; denota-se que para a maioria das bacias analisadas, os valores da distribuição dessa variável encontraram-se próximo nos diferentes métodos. 
Segundo Braz et al. (2007), essa constatação indica que a disposição espacial das estações pluviométricas analisadas apresenta-se em forma homogênea na maioria das bacias hidrográficas.

Como exceção a esse fato, a Bacia Hidrográfica do Rio Roosevelt foi a que apresentou valores mais discrepantes, gerado devido à baixa densidade de pluviômetros nessa área (TIBÚRCIO; CASTRO, 2007). Além disso, esse fato também pode ter ocorrido devido a essa mesma região possuir transições de elevações mais bruscas, como pode ser visualizado na Figura 4, gerando dessa forma um terreno mais acidentado o que torna, segundo Tucci (2009), os valores de intensidade média da bacia hidrográfica, obtidos pela técnica de $\mathrm{P}$. T. divergentes dos aferidos pelas isoietas.

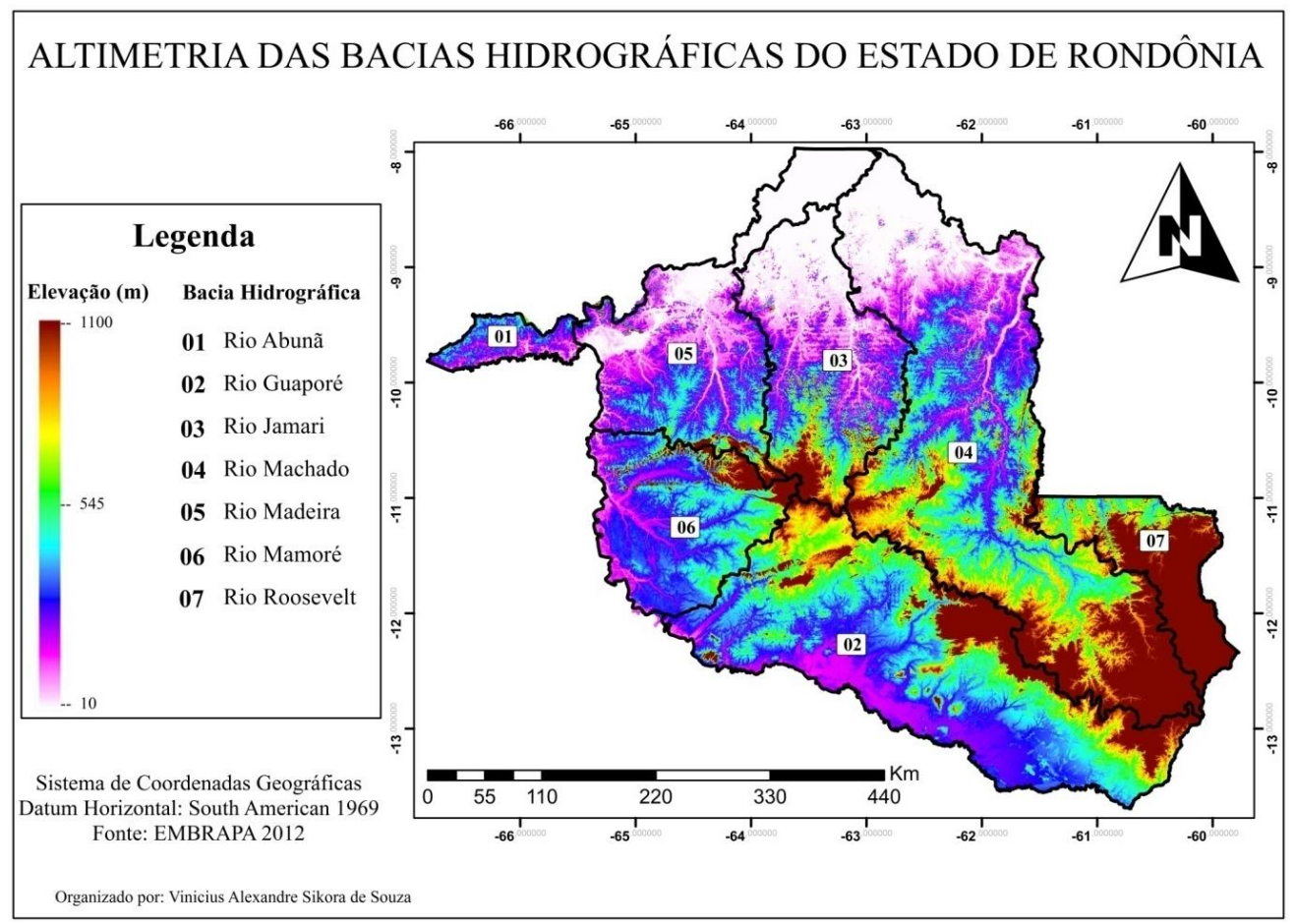

Figura 4 - Elevação das bacias hidrográficas do estado de Rondônia.

Nesse aspecto as regiões das bacias hidrográficas dos rios Machado e Madeira pela existência de extensas planícies, apresentaram os valores de intensidades médias mais próximas por essas técnicas.

Porém cabe ressaltar que as anomalias observadas na Tabela 5 não são estaticamente significativas, pois o valor-p obtido para o teste de $\mathrm{K}-\mathrm{W}$ foi de 0,660 , sendo este bem maior que o nível de significância estabelecido, o que denota que os resultados obtidos pelas diferentes técnicas são estatisticamente idênticos, resultado semelhante foi evidenciado pelo teste de Dunn, pois o mesmo indicou inexistência de diferenças em suas análises de pares, reforçando dessa forma que as diferenças observadas não são estatisticamente significativas. 
Os dados explicitados na Tabela 5 revelam ainda que a Bacia do Rio Jamari apresenta eventos extremos de maior magnitude média quando comparadas as outras bacias hidrográficas, indicando assim que do ponto de vista do volume total das chuvas, há necessidade de maior preocupação com o controle de enxurradas e conservação do solo nessa localidade do estado de Rondônia (CARDOSO; ULLMANN; BERTOL, 1998).

Portanto, dadas as características da precipitação analisadas, essa bacia hidrográfica está mais propensa a sofrer mudanças das características das pastagens; a perda de qualidade dos corpos hídricos, devido ao carregamento de sedimentos que prejudicam a vida das espécies de fauna aquática; a deterioração das estradas de terra; e perda de hábitats e perda de biodiversidade local (CARVALHO, 2008).

\section{CONSIDERAÇÕES FINAIS}

Os dados das estações pluviométricas que se localizam no estado de Rondônia revelaram que a média das chuvas máximas de "um dia" encontrou-se variando de aproximadamente 71,3 a 173,5 mm/dia. Além disso, observou-se na série histórica analisada possíveis interferências de fenômenos climáticos como o El Niño e La Niña, o que podem ter gerado respectivamente as reduções e aumentos na ocorrência de eventos pluviométricos extremos.

Constatou-se nesse estudo que chuvas de alto fator erosivo, duração de 5 min e tempo de retorno de 2 anos, aumentam sua intensidade ao se aproximarem da região mais ao norte do estado, o que denotou que as mesmas são influenciadas pela Zona de Convergência Intertropical. Ainda em relação a esses eventos verificou-se que a Bacia do Rio Jamari, quando comparada com as demais bacias hidrográficas do estado de Rondônia, apresenta chuvas extremas de maior magnitude média, indicando dessa forma a necessidade de maior preocupação com o controle de enxurradas e conservação do solo nessa localidade do estado de Rondônia.

Para trabalhos futuros recomenda-se a instalação de estações pluviométricas com registros menores que um dia, a fim de confirmar os resultados obtidos, visto que os dados de precipitações menores que um dia foram obtidos de forma sintética, dessa forma, podem não corresponder fielmente as características da região em estudo. Além disso, aconselha-se que sejam instaladas estações pluviométricas na região mais ao norte de Rondônia, pois devido à inexistência nessa região, a mesma não foi contemplada como uma área de influência por alguma das equações estimadas. 


\section{REFERÊNCIAS}

AGUIAR, R. G.; VON RANDOW, C.; PRIANTE FILHO, N.; MANZI, A. O.; AGUIAR, L. J. G.; CARDOSO, F. L. Fluxos de massa e energia em uma floresta tropical no sudoeste da Amazônia. Revista Brasileira de Meteorologia, v. 21, p. 248$257,2006$.

ALMEIDA, A. Q.; RIBEIRO, A.; PAIVA, Y. G. ; RASCON, N. J. L.; LIMA, E. P. Geoestatística no estudo de modelagem temporal da precipitação. Revista Brasileira de Engenharia Agrícola e Ambiental, v. 15, n. 4, p. 354-358, 2011.

ARANTES, E. J.; PASSIG, F. H.; CARVALHO, K. Q.; KREUTZ, C. ; ARANTES, E. A. Análise das chuvas intensas da região noroeste do Paraná. OLAM - Ciência \& Tecnologia, n. Esp., p. 31-47, 2009.

BACK, A. J. Seleção de distribuição de probabilidade para chuvas diárias extremas do estado de Santa Catarina. Revista Brasileira de Meteorologia, v. 16, n. 2, p. 211-222, 2001.

BERGAMASCHI, H.; DALMAGO, G. A.; BERGONCI, J. I.; BIANCHI, C. A. M.; MÜLLER, A. G.; COMIRAN, F.; HECKLE, B. M. M. Distribuição hídrica no período crítico do milho e produção de grãos. Pesquisa Agropecuária Brasileira, Brasília, v. 39, n. 9, p. 831-839, 2004.

BERNINI, $\mathrm{H}$ et al. Avaliação e características de eventos extremos de Precipitação no perímetro urbano de Porto Velho - RO a partir da rede de pluviógrafos local. In: Simpósio Brasileiro de Recursos Hídricos, 2013, Bento Gonçalves, Anais..., Bento Gonçalves: ABRH, 2013.

BRANDÃO, C.; RODRIGUES, R.; COSTA, J. P. Análise de fenómenos extremos precipitações intensas em Portugal Continental. Lisboa: Direcção dos Serviços de Recursos Hídricos, 2001.

BRASIL. Departamento Nacional de Produção Mineral. Projeto RADAMBRASIL, Levantamento de Recursos Naturais. Folha SC - 20: Porto Velho. Rio de Janeiro, v. 16, 1978.

BRAZ, R. L.; RIBEIRO, C. A. D.; FERREIRA, D. S.; CECILIO, R. A. Uso de séries históricas e técnicas de SIG no estudo da distribuição temporal e espacial da pluviosidade na bacia Barra Seca localizada ao norte do Estado do Espírito Santo. In: ENCONTRO LATINO AMERICANO DE INICIAÇÃO CIENTÍFICA, $11 .$, 2007, São José dos Campos. Anais..., São José dos Campos: UNIVAP, 2007.

BUTT, N.; OLIVEIRA, P. A.; HEIL COSTA, M. H. Evidence that deforestation affects the onset of the rainy season in Rondônia, Brazil. Journal of Geophysical Research, v. 116, n. D11120, p. 1-8, 2011. 
CARDOSO, C. O.; ULLMANN, M. N.; BERTOL, I. Análise de chuvas intensas a partir da Desagregação das chuvas diárias de Lages e de Campos Novos (SC). Revista Brasileira de Ciência do Solo, Viçosa, v. 22, n. 1, p. 131-140, 1998.

CARVALHO, E. T. L. Avaliação de elementos de infiltração de águas pluviais na zona norte da cidade de Goiânia. Goiânia: UFG, 2008.

Dissertação (Mestrado em Geotécnica e Construção Civil), Escola de Engenharia Civil, Universidade Federal de Goiás, 2008.

COHEN, J. C. P.; BELTRÃO, J. C.; GANDU, A. W.; SILVA, R. R. Influência do desmatamento sobre o ciclo hidrológico na Amazônia. Ciencia e Cultura, São Paulo, v. 59, n. 3, 2007.

COSTA, A. C.; DURÃO, R.; PEREIRA, M. J.; SOARES, A. Using stochastic spacetime models to map extreme precipitation in southern Portugal. Natural Hazards and Earth System Sciences, v. 8, p. 763-773, 2008.

CUTRIM, E. M. C.; MOLION, L. B.; NECHET, D. Chuvas na Amazônia Durante o Século XX. In: CONGRESSO BRASILEIRO DE METEOROLOGIA, 11., Rio de Janeiro, 2000. Anais..., Rio de Janeiro: SBMET, 2000.

DE OLHO NO TEMPO. 23:00 - ALERTA de chuva intensa para Porto Velho. Disponível em: < http://wwwdeolhonotempo.blogspot.com/2007/02/2300alerta-de-chuva-intensa-para-porto.html>. Acesso em: 20 jan. 2011.

FERREIRA, J. S. W. Globalização e urbanização subdesenvolvida. São Paulo Perspec., v. 14, n. 4, 2000

FIETZ, C. R.; COMUNELL, E. Probabilidade de ocorrência de chuva em Mato Grosso do Sul. Dourados: Embrapa Agropecuária Oeste, 2006.

GAMA, M. J. Clima. In: Atlas Geoambiental de Rondônia. 2. ed. Porto Velho: SEDAM, 2003.

GRAPHPAD PRISM. Graphpad Software Inc. San Diego: [s.n.], 2007.

GRIMM, A. M.; TEDESCHI, R. G. Influência de eventos El Niño e La Niña sobre a frequência de eventos extremos de precipitação no Brasil. In: CONGRESSO BRASILEIRO DE METEOROLOGIA, 13., 2004, Fortaleza. Anais..., Fortaleza: SBMET, 2004.

HERNANDEZ, V. Regionalização dos parâmetros de escala em chuvas intensas. Revista Brasileira de Recursos Hídricos. v. 13 n. 1, p. 91-98, 2008.

IBGE. Instituto Brasileiro de Geografia e Estatística. Cidades por Unidades Federativas. Disponível em:

<http://www.ibge.gov.br/cidadesat/topwindow.htm?1>. Acesso em: 20 jun. 2011.

MEHL, H. U.; ELTZ, F. L. F.; REICHERT, J. M.; DIDONÉ, I. A. Caracterização de padrões de chuvas ocorrentes em Santa Maria (RS). Revista Brasileira de Ciência do Solo, Viçosa, v. 25, n. 1, p. 475-483, 2001. 
NAGHETTINI, M.; PINTO, E. J. A. Hidrologia Estatística. Belo horizonte: CRPM, 2007.

OliveirA, J. P. B.; CeCílio, R. C.; XAVIER, A. C.; JASPER, A. P. S.; OliveirA, L. B. Precipitação provável para Alegre-ES através da distribuição de probabilidade gama. Engenharia, v. 7, n. 2, p. 204-211, 2010.

OLIVEIRA, L. F. C.; VIOLA, M. R.; PEREIRA, S.; MORAIS, N. R. Modelos de predição de chuvas intensas para o estado do Mato Grosso, Brasil. Ambi-Agua, Taubaté, v. 6, n. 3, p. 274-290, 2011.

RONDÔNIA. Secretaria de Estado do Desenvolvimento Ambiental (SEDAM). Boletim Climatológico de Rondônia - 2008. Porto Velho: SEDAM, 2009.

SANTOS, I. A.; BUCHMAN, J. Uma Revisão Qualitativa Enfatizando Aspectos Climáticos da Amazônia e da Região Nordeste do Brasil. Anuário do Instituto de Geociências - UFRJ, v. 33, n. 2, p. 09-23, 2010.

SANTOS NETO, L. A.; MORAES, J. C.; NOBREGA, R. S. A Ação Antrópica na Região Central de Rondônia e a Resposta Climática. In: CONGRESSO BRASILEIRO DE METEOROLOGIA, 16., 2010, Belém. Anais..., Belém: SBMET, 2010.

SANTOS, M. A urbanização brasileira. 5. Ed. São Paulo: EDEUSP, 2008.

SHERMAN, G. E.; SUTTON, T.; BLAZEK, R.; LUTHMAN, L. Quantum GIS User Guide - Version 1.7.2. Seamus, 2011.

SILVA, M. J. G.; SARAIVA, F. M.; SILVA, A. A. G. Estudo do Comportamento da Precipitação para o ano de 2005 no estado de Rondônia. In: CONGRESSO BRASILEIRO DE METEOROLOGIA, 16., 2010, Belém. Anais..., Belém: SBMET, 2010.

SILVA, L. P.; ZUFFO, C. E. Recursos hídricos: conservando para o futuro. In: Atlas Geoambiental de Rondônia . 2. ed. Porto Velho: SEDAM, 2003

TIBÚRCIO, E. C.; CASTRO, M. A. H. Uma Aplicação de SIG para Determinação de Altura Pluviométrica Média em Bacias Hidrográficas. In: SIMPÓSIO BRASILEIRO DE RECURSOS HÍDRICOS, 17., 2007, São Paulo. Anais..., São Paulo: $A B R H, 2007$.

TUCCI, C. E. M. (Org.). Hidrologia. Ciências e aplicação. 4. Ed. Porto Alegre: Ed. da Universidade: ABRH: EDUSP, 2009.

TUCCI, C. E. M. Águas urbanas. Estudos Avançados, v. 22, n. 63, p. 97-112, 2008

TUCCI, C. E. M. Inundações Urbanas. 1. Ed. Porto Alegre: ABRH, 2007.

WEBLER, A. D.; AGUIAR, R. G.; AGUIAR, L. J. G. Características da precipitação em área de floresta primária e área de pastagem no Estado de Rondônia.

Revista Ciência e Natura, v. Esp., p. 55-58, 2007. 
WERTH, D.; AVISSAR, R. The local and global effects of Amazon deforestation. Journal of Geophysical Research, v. 107, n. D20, p. 1-8, 2002.

XAVIER, T. M. B. S.; XAVIER, A. F. S.; DIAS, M. A. F. S.; DIAS, P. L. S. A Zona de Convergência Intertropical - ZCIT e suas relações com a chuva no Ceará (1964-98). Revista Brasileira de Meteorologia, v. 15, n. 1, p. 27-43, 2000.

XAVIER, T. M. B. S.; XAVIER, A. F. S.; DIAS, M. A. F. S.; DIAS, P. L. S. Interrelações entre eventos (ENSO), a ZCIT (ITCZ) no Atlântico e a chuva nas bacias hidrográficas do Ceará. Revista Brasileira de Recursos Hídricos, v. 8, n. 2, p. 111-126, 2003. 